\title{
STUDY OF SEMI-SYNTHETIC PLASTIC OBJECTS OF HISTORIC INTEREST USING NON-INVASIVE TOTAL REFLECTANCE FT-IR
}

\author{
Costanza Cucci ${ }^{(1)}$, Giovanni Bartolozzi ${ }^{(1)}$, Veronica Marchiafava ${ }^{(1)}$, Marcello Picollo ${ }^{(1)}$, \\ Emma Richardson ${ }^{(2)}$
}

(1) "Nello Carrara" Institute of Applied Physics of the Italian National Research Council (IFACCNR), Via Madonna del Piano 10, 50019 Sesto Fiorentino, Italy.

(2) Department of History of Art, University College London, Gower Street, London, WC1E 6BT.

Email addresses: c.cucci@ifac.cnr.it; g.bartolozzi@ifac.cnr.it; m.picollo@ifac.cnr.it; v.marchiafava@ifac.cnr.it, e.richardson@ucl.ac.uk

*Corresponding author: Costanza Cucci; email: c.cucci@ifac.cnr.it; Phone: +39-055 5226405

Keywords

Total Reflectance FT-IR spectroscopy, semi-synthetic polymers, plastics, non-invasive
identification, collections, spectral matching

\section{INTRODUCTION}

It is nowadays accepted that a wide range of plastic artistic objects, including not only modern and contemporary artworks, but also design, fashion, ethnographic items, as well as photographic supports, etc., are part of our cultural heritage. As such, these need to be preserved and included in dedicated conservation programs. However, a more comprehensive understanding of the extent of instability in such materials and the broader issues surrounding their preservation in cultural heritage has matured only in past two decades. Contextually, a new research branch focused on care of plastic objects in artistic and historical collections, has progressively grown. Although sporadic studies were carried during the early 1990's [1-3 a systematic approach to this challenge only really took hold in the 2000's [4-6] An important milestone in this context was the POPART (Preservation Of plastic ARTefacts in museum collections) Project, a 42-month international research project part funded by the European Commission [7], which aimed at defining widely accepted strategies of preservation and maintenance of plastic artworks in museum collections [8]. Among the priorities singled out within the POPART Project, the definition of protocols and techniques suitable for identification of the types of plastics constituting an artwork was considered crucial. Knowledge of materials is indeed essential for successful interventive conservation and for implementation of long-term preservation strategies. However, "plastics" include such a wide range of semi-synthetic and synthetic polymers, which can exhibit highly varied properties and behaviours, so that the ability to correctly establish the chemical composition of a plastic object can be a challenging task. This is magnified when dealing with artworks or historical plastic objects, since, in this case, plastics may be degraded and modified by aging in addition to combinations with other substances (adhesives, colorants, additives and mixtures with other materials, like metals, wood, etc.). In this context, the need for classification within heritage collections is of paramount importance. However, even simple identification of materials within these collections is not straightforward. In particular, an extensive and unresolved problem is the clear discrimination between natural materials and semi-synthetic polymers, classified as historic plastics.

The term plastic is the general name given to a variety of natural, synthetic and semi-synthetic materials, which, as the name suggests, exhibit plastic behaviour and can be moulded or shaped into a range of forms. The earliest plastics were naturally occurring and can be dated back to prehistoric times. For example horn, amber and tortoiseshell are all natural plastics that can be re-shaped using heat. The first plastics to be synthesised in the laboratory were based on natural polymeric materials, such as cellulose derived from wood pulp, or casein derived from milk products, which were chemically modified and used to create what we know as semi-synthetic plastics. These early man-made plastics were more often than not produced to mimic exotic and expensive materials, 
such as ivory and ebony [9]. In their early incarnations they were often given trade names such as Ivorine and Ebonite, illustrating their desired market and their direct link to material substitution.

Moreover, organic polymeric materials will all degrade over time, whether natural, semi-synthetic or synthetic. Semi-synthetic and synthetic types tend to pose significant stabilisation problems due to production methods, additives, and treatments, which can introduce varying and complex routes of degradation. For this reason it is crucial for the conservator to characterise the materials of construction, before an understanding of an artefact's technology can be determined or any conservation strategy put in place.

Procedures for identification and classification of plastics are needed not only prior to any conservation treatment of an artwork, but also to assist in the care of collections as a whole. Collection management strategies necessitate the segregation of polymers known to give off volatile components during their deterioration. For example, materials such as cellulose acetate undergo hydrolysis reactions in the presence of moisture, cleaving off acetic acid from the polymer molecule. Unless such material is identified and isolated, these acid groups can induce or exacerbate deterioration within other artefacts.

Nevertheless, the very nature of historic objects often constrains sampling and the visual appearance of imitation plastics means that it can be difficult to readily distinguish the polymer classes. For example, cellulose nitrate was often produced to resemble the layered structure of horn in decorative products.

Often experienced professionals are capable of identifying the type of plastic composing an aged object on the basis of simple practical tests, such as visual analysis, smelling, testing of mechanical properties (softness, rigidity, etc.), evaluation of degradation signs (cracking, crumbling, etc.) [5]. Nevertheless, in many cases this approach is insufficient, and a more detailed material analysis is required, although often coupled with other observations.

Analytical methods developed in other applicative sectors, such as manufacturing and the chemical industry, are routinely applied in the conservation field to aid characterisation of polymers. These methods may include chromatographic techniques, such as Pyrolysis Gas Chromatography Mass Spectrometry (Py-GCMS), or spectroscopic methods, like traditional Fourier-Transform Infrared Spectroscopy (FT-IR) in transmittance mode. More often than not these analytical methods are performed on fragments or micro-samples taken from the object $[8,10]$.

However, when dealing with museum objects, non-invasive or micro-destructive analytical methods would be preferred over sampling techniques Moreover, in the field of cultural heritage the recourse to fast in-situ analysis performed by using portable devices is highly recommended, since displacement and handling of museum objects is always undesired.

Taking into account all these aspects, a key activity within the POPART Project was the definition of new procedures and non-invasive methodologies specifically tailored for the identification and characterisation of plastics in collections and museum contexts [8,11-15]. In order to comparatively evaluate the different analytical techniques when used in this atypical context, a workbench was created: it consisted in a reference collection of typical polymeric materials - including synthetics, semi-synthetic plastics and some natural polymers - likely occurring in artworks or historical objects of cultural interest. This reference collection, named "SamCo" [16], included approximately 100 different samples, made of fully characterised and identified plastics, selected among the most common in museum collections. The entire set comprised two subgroups of samples: the "standards" and the "objects". The "standards" were pure polymers, belonging to commercial sets of identified resins (for example the ResinKit ${ }^{\mathrm{TM}}$ ) or created in the laboratory, whereas the "objects" consisted of samples of new and degraded plastics included to simulate actual/real conditions. The SamCo collection was replicated in several identical sets and distributed among the POPART consortium partners, making it an available tool for testing new methodologies and validating research on conservation of plastic artworks.

The present paper is contextualised in this research, and is aimed at evaluating the effectiveness of non-invasive reflectance FT-IR spectroscopy implemented by portable devices for assessing 
composition of unknown objects made from natural and semi-synthetic polymers. Indeed, a new generation of small, handheld and low cost FT-IR spectrophotometers has been recently marketed, thus opening new perspectives for a wide range of applications, including in-situ analysis in museum collections. However a number of issues related to the practical implementation of FT-IR technique operated in Total Reflectance (TR) mode still require to be examined.

In a recent study the authors proposed the use of portable FT-IR spectrophotometry operating in TR mode for non-invasive identification of plastic materials [17]. This pilot study, conducted on 50 standards of polymeric resins, demonstrated that portable TR FT-IR proves to be a promising technique, provided that suitable spectral archives are available and appropriate pre-processing treatment of data are adopted. Following this previous work, the present paper extends the same approach to a set of real case studies, and proposes a procedure for a straightforward preliminary classification of unknown plastics using TR FT-IR spectroscopy.

A set of ten heritage objects made from early semi-synthetic materials was selected to represent typical identification challenges occurring within the conservation sector. These objects were then used as a training test set to validate the experimental procedure proposed for identifying constituent polymers, which up until now had only been tested on standard reference materials. The training set was deliberately built to focus on the problem of identifying and discriminating early plastics and natural materials, and it included different examples of historical plastics. The first step involved compiling a suitable spectral library of TR FT-IR spectra acquired on the SamCo collection using the same experimental configuration to be used in situ. This spectral library was specifically tailored for classification of historic and degraded plastics.

This was followed by the acquisition and pre-processing of TR FT-IR spectra from the test objects. The pre-processed data were classified against the SamCo spectral library using the searching algorithms available for the automatic classification of spectra in commercial FT-IR spectroscopy software. This procedure was successfully applied to several cases, although residual uncertainties remained in few examples.

The results obtained are critically analysed and discussed from the perspective of proposing a robust method for in-field pre-screening of the chemical composition of plastic artistic and historical objects.

\section{MATERIALS AND METHODS}

\subsection{SAMPLES}

SamCo collection. A complete SamCo collection is available at IFAC-CNR, a partner in the POPART Project. SamCo consists of 30 standard materials from the commercial set ResinKit ${ }^{\mathrm{TM}}$ and 66 samples of reference materials including synthetic, semi-synthetic and natural polymers. The complete list of SamCo materials is reported in [8].

Test objects. Ten test objects, part of the Materials Library held at the Department of History of Art, University College London, were selected to simulate typical modern materials in cultural heritage. A list of each object is given in Table 1, accompanied by a description of the object's condition and their approximate date of production. The rationale for choosing these objects was their representation of the types of natural and semi-synthetic polymers often found within heritage collections and the challenges that they pose in terms of stability and identification.

\subsection{INSTRUMENTATION AND DATA PROCESSING}

The FT-IR spectra of the entire set of reference samples and objects were acquired by means of an Alpha Bruker Optics Spectrophotometer equipped with a SiC (Silicon Carbide) Globar source and a DTGS (Deuterated Tri-Glycine Sulphate) detector. All the reported spectra were non-invasively acquired in TR mode across the $7500-375 \mathrm{~cm}^{-1}$ range, with a $4 \mathrm{~cm}^{-1}$ resolution. Sixty-four scans were acquired for the background, while 128 scans were recorded on the samples in order to optimise the signal-to-noise ratio (Opus 7.0.122 software by Bruker Optics). All measurements 
were performed positioning the instrument at the optimal focusing distance $(15 \mathrm{~mm})$ from the analysed item using the head accessory supplied with the spectrophotometer, except for few cases where the use of the head was not possible. When the surface of the object precluded the use of the head, the optimal focus was achieved contactless via a digital camera linked to the instrument. Additionally, attenuated total reflectance (ATR) and transmittance FT-IR spectra were collected on selected objects.

Nicolet Ez Ominc ${ }^{\circledR} 7.3$ software was used for both spectra processing and automatic search. All the TR spectra were pre-treated by removing the $\mathrm{CO}_{2}$ spectral contribution, by applying the SavitzkyGolay smoothing algorithm (using 15 points), and by applying the automatic baseline correction. Subsequently, the Kramers-Krönig (KK) algorithm was applied in the 4000-400 $\mathrm{cm}^{-1}$ range [18], The KK transformed spectra are more easily interpretable and are directly comparable with any commercial reference FT-IR spectral databases

The reference spectral database was custom built by incorporating the FT-IR spectra of the SamCo samples measured in TR mode. An additional FT-IR spectrum corresponding to Regenerated Cellulose was obtained from the IRUG Spectral Library [19]. The search tool of OMNIC interface was used to find the best match between unknown spectra and spectra included in the custom-built database. The search method uses the Correlation algorithm to rate the similarity between the unknown spectrum and each entry in the reference spectral library. The quality of the match is expressed with a number ranging from 0 to 100 (perfect match), which was adopted as metric to rank the similarity between spectra in the present study [20-21]. The first three best results have been reported for each analysed case.

\section{RESULTS AND DISCUSSION}

\subsection{EARLY PLASTICS AND IMITATION MATERIALS}

As previously discussed many of the early synthesised plastics were intended to provide cost effective, easily accessible alternatives to more exotic natural materials. Polymers such as cellulose nitrate and cellulose acetate were often employed to replace natural materials such as ivory, tortoiseshell and horn. The visual characteristics were mimicked through polymer processing and through the inclusion of additives such as pigments, dyes and opacifiers. The lack of morphological features that semi-synthetic and synthetic polymers possess inevitably means that identification of such material is often difficult. When coupled with processing procedures designed to mimic the visual characteristics of natural plastics these concerns are often magnified.

The results presented here serve as case studies to highlight some of the key issues relating to identification of semi-synthetic materials in heritage collections.

\subsection{CELLULOSE NITRATE}

\subsubsection{DECORATIVE HAND MIRROR AND DECORATIVE MECHANIZED FAN}

At the beginning of the $20^{\text {th }}$ century cellulose nitrate took over from natural plastics as the dominant material for decorative household items. Its low production costs and thermoplastic properties meant that it could be moulded into three dimensional forms or transparent, flexible sheets at a low cost and in high quantities. Cellulose nitrate was often processed in a layered form designed to mimic the structure of horn. Coupled with the fact that horn and other keratin materials had the propensity to warp and crack, cellulose nitrate quickly took over as the material of choice [9].

As examples of this class of historical plastics, the decorative hand mirror (Object 2) and the decorative mechanised fan (Object 8) were included in the training set (Figure 1). Both of these objects were showing significant signs of degradation.

The hand mirror exhibited classic signs of cellulose nitrate degradation, such as crazing, and corrosion of the metal foil caused by outgassing during denitration. The mechanized fan was 
showing signs of plasticiser migration as an oily exudate on the surface, which was accompanied by embrittlement, and has resulted in the loss of a number of the fan's blades.

Although their physical forms showed considerable deterioration, it is clear from the TR FT-IR spectra that the polymer still displays characteristic vibrations (see Table 2) [22-24] enabling ready identification when compared to a suitable reference sample. This is confirmed by the results obtained with the application of OMNIC Search tool to the TR FT-IR spectra of the two objects against the SamCo spectral library. As shown in Table 1, in both cases the spectral matching identified the plastics as cellulose nitrate. In Figure 2 the TR FT-IR spectrum acquired from Object 2 is reported and compared with its best matching FT-IR spectrum in the database. As reported in Table 2, the typical bands attributable to the nitrate group and to the tetrahydropyran ring of the cellulose are clearly identifiable.

It can also be noticed that, for both the objects, the best match was given with SamCo n. 58A, which was a real object (ruler) made of cellulose nitrate, thus likely more degraded than the reference material (SamCo n. 9), occurring at the second place of the best matching list. Moreover, the third result is horn, with very similar scores for both the objects. This would suggests that, even if the Objects 2 and 8 are dissimilar from each other and likely underwent different degradation processes, their TR FT-IR spectra displayed strong spectral similarities.

\subsection{CELLULOSE ACETATE}

During the 1930s the use of cellulose nitrate was superseded by cellulose acetate. The highly flammable nature of cellulose nitrate materials meant that there was a demand for alternatives for use in the polymer industry, with cellulose acetate providing a non-flammable substitute. The applications for cellulose acetate were similar to those of cellulose nitrate owing to their comparable optical and physical qualities.

\subsubsection{IMITATION TORTOISESHELL SUNGLASSES}

Tortoiseshell has been used since antiquity as a decorative material, with its thermoplastic properties enabling thin sheets to be deformed and used for inlay and fancy goods. Primarily derived from the Hawksbill turtle, the market for this colourful, transparent and malleable material has caused its demise and this turtle is now considered an endangered species. Long before the ban on the trade of tortoiseshell introduced during the 1970s [25], there was a high demand for imitation tortoiseshell products for low cost goods. The transparent nature of cellulose acetate made it an ideal replacement for tortoiseshell because it could easily be dyed to replicate the natural shell's mottled effects.

The imitation tortoiseshell sunglasses (Object 1) shown in Figure 3 exhibited typical mechanical failure of cellulose acetate plastic, which is often accompanied by the migration of additive material from the bulk. The visual inspection of this highly degraded object, together with a historical contextualization of this fashion accessory, lead to hypothesise that its original constituting material is cellulose acetate. However, in this case the TR FT-IR spectrum did not provide a straightforward interpretation. As shown in Table 1, the best spectral matching with the available spectral library is obtained with the spectrum of regenerated cellulose (RC) rather than, as expected, chemically modified cellulose [22-24]. As shown in Figure 4 and in Table 3 the characteristic spectral features of RC are observable in the TR FT-IR spectrum acquired on the Object 1, while no traces of the bands corresponding to the acetate group are detectable.

However, this result appears anomalous with the use of $\mathrm{RC}$ for frames manufacturing, with $\mathrm{RC}$ finding primary application in thin film material and fibres. It is therefore proposed that the sunglasses are in fact cellulose acetate that has undergone deacetylation overtime, reverting to a form similar to cellulose [26,27] and thus exhibiting spectral vibrations comparable to regenerated cellulose. Similar findings have been reported by Price et al [28] who demonstrated the deacetylation of a pigmented cellulose acetate film within a five year interval of acquiring an IR spectrum. They showed the clear formation of $\mathrm{O}-\mathrm{H}$ bands at $3360 \mathrm{~cm}^{-1}$ and broadened $\mathrm{C}-\mathrm{O}$ stretches 
at $1240 \mathrm{~cm}^{-1}$ and $1055 \mathrm{~cm}^{-1}$, accompanied by a complete loss of the $\mathrm{C}=\mathrm{O}$ vibration at $1750 \mathrm{~cm}^{-1}$. Being that the TR FT-IR spectrum proved difficult to interpret, an additional FT-IR spectrum was acquired in transmittance mode on small fragments crumbling from the main object. The analysis of transmittance FT-IR spectrum allowed to identify also the presence of triphenyl phosphate (TPP) crystals, with spectral bands apparent at $1590,1490,1455 \mathrm{~cm}^{-1}(\mathrm{C}=\mathrm{C}$ stretching $), 1295 \mathrm{~cm}^{-1}(\mathrm{P}=\mathrm{O}$ stretching), $1194 \mathrm{~cm}^{-1}$ (P-O stretching), 1026, $1010 \mathrm{~cm}^{-1}$ (aromatic C-H in plane bending), $964 \mathrm{~cm}^{-1}$ (O-Ph stretching) and 900, $690 \mathrm{~cm}^{-1}$ (aromatic C-H out of plane bending). This finding supported the hypothesis that the glasses were originally constructed from cellulose acetate [29]. Indeed, historically, triphenyl phosphate crystals have been most commonly used in conjunction with cellulose acetate as a flame retardant, or as a replacement for camphor in cellulose nitrate [30], often found in the presence of liquid plasticisers to help reduce the type of recrystallization and blooming seen here [31].

The analysis of these heavily degraded glasses provided an important illustration of the problems encountered when characterising degraded material. The nature of historic objects means that collections demonstrate an array of ageing and degradation processes, accompanied by alterations in the underlying structure. As such, spectroscopic techniques employed for identification purposes will inevitably detect these alterations, which in some cases may result in false positive results. These non-ideal materials demonstrate the need for a boarder understanding of the history, technologies, and degradative processes of objects within collections in order to further support spectral analysis and interpretation.

\subsubsection{IMITATION IVORY PLAYING CARDS AND DECORATIVE KNIFE HANDLE}

The playing cards (Object 9) and the decorative knife (Object 10), shown in Figures 5, had both been catalogued within the Materials Library (Section 2.1) as imitation ivory constructed from cellulose acetate [32]. The FT-IR analysis showed that the polymer in each case is not in fact an imitation plastic, but genuine ivory. The spectra acquired from both the playing cards and the knife handle showed the typical absorption bands attributable to calcium phosphate and to protein-based materials (Figure 6 and Table 4) [24].

The results of the searching algorithm applied to the two unknown spectra against the reference spectral library also indicated that the objects are likely made of a natural material (ivory), thus discarding the first hypothesis regarding cellulose acetate.

The results of these analyses serve to strengthen the need for a holistic approach to materials classification and cataloguing. The initial misclassification of these objects based on visual analysis alone could be corrected through non-invasive spectroscopic techniques, thus indicating the importance of an integrated management programme within collections. The differing requirements of collections necessitate robust identification in order to ensure safe strategies for conservation, storage and display.

\subsection{CASEIN FORMALDEHYDE}

\subsubsection{TOY COUNTERS AND DECORATIVE BUTTONS}

Casein formaldehyde is a rigid, thermosetting semi-synthetic plastic, which came onto the market in 1900 as a cheap alternative to horn and hardened rubber. It was derived from soluble casein protein extracted from dairy products which was subsequently plasticised with water and dyes, and crosslinked in its cast form with formaldehyde via a process termed formolisation [31]. It was sold commercially under the name of Galalith, taken from the Greek words gala (milk) and lithos (stone), denoting the white, stone-like properties of the plastic [6]. The wide availability of dairy products made casein formaldehyde historically cheap to produce, but production slowed, due to the demand for milk products during the First and Second World Wars. After the Second World War this material was quickly superseded due to a wealth of plastics made available as a result of military research. One of its greatest drawbacks was its high moisture uptake, which meant that it 
could not be used in technical applications, such as cog wheels, due to significant dimensional changes [6]. However, one commercial benefit of the hydrophilic nature of the polymer is its capacity to be readily dyed with water-soluble colorants. Hence, casein formaldehyde does continue to be used within the clothing industry for the production of buttons.

Figure 7 shows the Galalith toy counters (Object 5) and the decorative buttons (Object 6 and 7). The TR FT-IT spectra acquired from these objects are almost superimposable. Figure 8 shows the TR FT-IR spectra acquired on Object 5 compared with the casein formaldehyde spectrum of the SamCo reference database. As reported in detail in Table 5 it is possible to see Amide I and Amide II vibrations across the spectral region of $1650-1500 \mathrm{~cm}^{-1}$ and other characteristic bands of a proteinbased material [24]. In this case, casein formaldehyde high affinity to moisture can be seen as a large O-H band superimposed across $3600-2800 \mathrm{~cm}-1$ in the FT-IR spectrum. In fact, its high moisture uptake can also lead to staining and watermarks, as evidenced in the green buttons in Figure 7, which are likely to have been caused during their washing with textile garments.

However, in this case, the spectral matching algorithm returned a match of horn for all samples as their highest correlation, with their closest second match being casein formaldehyde (Table 1). This is not surprising, since TR FT-IR spectra of horn and casein formaldehyde exhibit strong similarities due to their underlying protein structures. This example indicates that the application of searching algorithms must be undertaken with caution and cannot be used as black box method, as it still requires a significant amount of user experience [33, 34]. For the three examples under analysis, accurate visual inspection and contextualization of objects eliminated any doubt on the possible natural origin of constituting materials, and the hypothesis of horn could be easily discarded.

\subsection{RUBBER GLOVES}

The first documented use of natural rubber dates back to the $6^{\text {th }}$ century in South America, where it is understood to have been used by the Aztecs for sacrificial objects and vessels [6]. Historically, natural rubber has found extensive application [35], but it was not until the $19^{\text {th }}$ century that the properties of rubber were intentionally manipulated to produce a material capable of holding its form whilst maintaining its elastic properties. In his early experiments, Charles Goodyear modified natural rubber using sulphur and white lead, producing an elastomer chemically interspersed with crosslinks in a process now known as vulcanization.

There are several elastomeric and rubbery materials now available on the market, covering semisynthetic and synthetic types, which makes identification within heritage collections a challenge.

In this case, TR FT-IR was employed to identify the specific class of rubber used in the manufacturing of the almost undegraded and heavily degraded gloves, shown in Figure 9 (Objects 3 and 4, respectively). In Figure 10 the spectra acquired from the two objects are compared with the best matching spectrum in the SamCo database.

The primary bands seen in the TR FT-IR spectra are listed in Table 6, the gloves exhibiting characteristic vibrations for a hydrocarbon polymer. The spectral matching algorithm provided a match of polyethylene, of varying degrees of density, as the closest match for these two gloves. However, the flexibility of the undegraded glove and the clear embrittlement and yellowing seen in the other glove suggested that this is not polyethylene. The low number of spectral vibrations relating to aliphatic stretching and bending indicated that the polymer is likely to be ethylenepropylene-diene (EPDM) rubber [36, 37]. which is chemically similar to polyethylene, but has a distinctly different molecular structure. Although the spectral matching indicated the presence of polyethylene, and EPDM is often co-polymerised with vulcanised polyethylene material [31], the spectrum of the undegraded sample (Figure $10 \mathrm{~A}$ ) does not exhibit vibrations related to the crosslinked network in the hard phase [38]. Cross-linking with polyethylene is normally carried out using peroxides or radiation, not sulphur, which would introduce oxygenated species along the polymer backbone. 
The spectra of the heavily degraded glove, which showed an extensive discolouration (Figure $10 \mathrm{~B}$ ) exhibit a weak $\mathrm{C}=\mathrm{O}$ carbonyl vibration around $1700 \mathrm{~cm}^{-1}$. This is highlighted in Figure 11, where the spectra of un-degraded and heavily degraded samples are compared in the $1350-1950 \mathrm{~cm}^{-1}$ range.

Zhao et al have reported similar spectral alterations and oxidation behaviour in EPDM exposed in artificial weathering environments using UV radiation [36]. In their study they also monitored the accompanying colour change using spectrophotometry and found a shift towards the red on degradation.

\section{CONCLUSIONS}

Due to the number of different polymer classes comprising modern and contemporary art and artefacts, coupled with their wide range of behaviours, the issues facing conservators and curators of $20^{\text {th }}$ century collections are varied. As in the case studies presented here, the very nature of imitation plastics can hider visual methods of identification, especially where the physical form of an artefact often restricts the removal of a representative sample. This illustrates the need for noninvasive methods of characterisation, readily enabling collections surveys and providing conservators with a means of materials identification to inform decisions regarding preventive and interventive treatment.

The present work discusses a semi-automated procedure for the identification of unknown plastics based on the non-invasive TR FT-IR spectroscopic technique, and integrated with a built on purpose spectral library containing TR FTIR spectra of the SamCo collection, specifically tailored for classifying plastics in collections.

A set of previously classified ten heritage objects, belonging to the Materials Library of the Department of History of Art, University College London, was used as training set to corroborate the proposed procedure and to check its applicability to real objects.

The application of TR FT-IR spectroscopy, coupled with the custom reference library made it possible to classify unknown samples. Provided that suitable spectral pre-processing is applied to TR spectra, as proposed in this paper, the automated searching algorithm proved to be helpful in classification. Although automated search algorithms are designed to be objective, their optimisation and application is still somewhat subjective. Unknowns are always assigned, regardless of whether a suitable reference is held within the data set, therefore a cautious approach is required with visual confirmation by the operator. For the objects studied here, the TR spectra in most cases remained characteristically distinct, enabling positive identification. In other cases, with heavily degraded materials, exemplified by the sunglasses' frames, spectral alterations may prevent ready identification, and the procedure leaves residual uncertainties that have to be solved with a holistic approach to their characterisation.

\section{ACKNOWLEDGMENTS}

The research presented has been based partially on materials obtained within the framework of the EC Project POPART Project (FP7/2007-2013, grant agreement $n^{\circ} 21221$ ), financed by the European Community, and the "Preventive Conservation of Contemporary Art" Project (COPAC, 2011-2013) financed by the Regione Toscana (Tuscan Region, Italy) in framework of the PAR-FAS Regional Project (2007-2013). 


\section{REFERENCES}

[1] S. Blank, An introduction to plastics and rubbers in collections, Studies in Conservation, 38 (1990) 53-63.

[2] D.W. Grattan, Saving the twentieth century: the conservation of modern materials, Canadian Conservation Institute, Ottawa, Canada, 1991.

[3] I. Hummelen, D. Sillé, Modern art: who cares?, Stichting Behoud Modern Kunst/Instituut Collectie Nederland, Amterdam, 1999.

[4] C. Rogerson, P. Garside, The Future of the 20th Century: Collecting, Interpreting and Conserving Modern Materials, Archetype Publications, London, 2005.

[5] Y. Shashoua, Conservation of Plastics: Materials Science, Degradation and Preservation Butterworth-Heinemann, Oxford, 2008.

[6] F. Waentig, Plastics in Art, Michael Imhof Verlag, Petersburg, 2009.

[7] POPART: Preservation of Plastic Artefacts in Museum Collections.

[8] B. Lavedrine, A. Fournier, G. Martin, POPART: Preservation of Plastic Artefacts in Museum Collections, Le Comite des Travaux Historiques et Scientifiques, Paris, 2012.

[9] J.L. Meikle, American Plastic: A Cultural History, Rutgers University Press, New Jersey, 1995

[10] G. Mitchell, F. France, A. Nordon, P. L. Tang, L. T Gibson, Assessment of historical polymers using attenuated total reflectance-Fourier transform infra-red spectroscopy with principal component analysis, Heritage Science, 1:28,(2013)

[11] C. Cucci, L. Bigazzi, M. Picollo, Fibre Optic Reflectance Spectroscopy as a non-invasive tool for investigating plastics degradation in contemporary art collections: A methodological study on an expanded polystyrene artwork, Journal of Cultural Heritage, 14 (2013) 290-296.

[12] L. Cséfalvayová, M. Strlič, H. Karjalainen, Quantitative NIR Chemical Imaging in Heritage Science, Analytical Chemistry, 83 (2011) 5101-5106.

[13] M. Schilling, M. Bouchard, H. Khanjian, T. Learner, A. Phenix, R. Rivenc, Application of Chemical and Thermal Analysis Methods for Studying Cellulose Ester Plastics, Accounts of Chemical Research, 43 (2010) 888-896.

[14] V. Šuštar, J. Kolar, L. Lusa, T. Learner, M. Schilling, R. Rivenc, H. Khanjian, D. Koleša, Identification of historical polymers using Near-Infrared Spectroscopy, Polymer Degradation and Stability, 107 (2014) 341-347.

[15] S. Williams, On-site non-destructive Mid-IR spectroscopy of plastics in museum objects using a portable FTIR spectrometer with fiber optic probe, MRS Proceedings, 462 (1996) 25.

[16] A. Lagana, B. Keneghan, Which plastics are in my collection? the need for a plastic reference sample collection (SamCo), in: B. Lavedrine, A. Fournier, G. Martin (Eds.) POPART: Preservation of Plastic Artefacts in Museum Collections, Le Comite des Travaux Historiques et Scientifiques, Paris, 2012, pp. 37-42.

[17] M. Picollo, G. Bartolozzi, C. Cucci, M. Galeotti, V. Marchiafava, B. Pizzo, Comparative Study of Fourier Transform Infrared Spectroscopy in Transmission, Attenuated Total Reflection, and Total Reflection Modes for the Analysis of Plastics in the Cultural Heritage Field, Appl. Spectrosc., 68 (2014) 389-396.

[18] M.R. Derrick, D. Stulik, J.M. Landry, Infared Spectroscopy in Conservation Science, Getty Conservation Institute, Los Angeles, 1999.

[19] B.A. Price, B. Pretzel, IRUG: Infrared \& Raman Users Group Spectral Database, Philadelphia, 2007

[20] Using OMNIC Algorithms, Thermo Electron Corporation, 2006

[21] Smith, Brian C. Infrared spectral interpretation: a systematic approach, CRC press, 1998.].

[22] M. Fan, D. Dai, B. Huang, Fourier Transform Infrared Spectroscopy for Natural Fibres, in Fourier Transform - Materials Analysis, In Tech, 2012 (2012) 45-68.

[23] M. Kacurakova, S.A. C., G.M. J., W.M. H., Molecular interactions in bacterial cellulose composites studied by 1D FT-IR and dynamic 2D FT-IR spectroscopy, Carbohydrate Research, 337 (2002) 1145-1153. 
[24] R.M. Silverstein, F.X. Webster, Spectrometric Identification of Organic Compounds, John Wiley \& Sons Inc, 1998.

[25] Convention on International trade in Endagered Specied of Wild Fauna and Flora, Washington, D.C, 1973

[26] P.Z. Adelstein, J.M. Reilly, F.G. Emming, Stability of Photographic Film: Part VI - Long Term Aging Studies, Society of Motion Picture and Television Engineers Journal, April (2002) 136-143.

[27] P.Z. Adelstein, J.M. Reilly, D.W. Nishimura, C.J. Erbland, Stability of cellulose ester base photographic film: Part III - measurement of film degradation, SMPTE Journal, 104 (1995) 281291.

[28] B.A. Price, S. Malenka, K. Sutherland, A. Lins, J.H. Carlson, Naum Garbo's Construction in Space: Two Cones: History and Materials, in: B. Keneghan, L. Egan (Eds.) Plastics: Looking at the Future and Learning from the Past, Archetype, London, 2007, pp. 81-88.

[29] J.S. Pegum, Contact Dermatitis from Plastics Containing Tri-Aryl Phosphates, British Journal of Dermatogology, 78 (1966) 626-631.

[30] A. Nakamura, International Programme on Chemical Safety: Triphenyl Phosphate, National Institute for Hygenic Sciences, 1991.

[31] J. Brydson, Plastics Materials, $7^{\text {th }}$ ed., Butterworth-Heinemann, Oxford, 1999.

[32] P. Simpson, Studies of the Degradation of Horn, Antler and Ivory at Archaeological Sites, PhD Diss.,University of Portsmouth, 2011.

[33] K.H. Esbensen, Multivariate Data Analysis: In Practice, 5th ed., Camo, Esbjerg, 2002.

[34] E. Richardson, G. Martin, P. Wyeth, On-site Collections Management: NIR Characterisation and Condition Monitoring of Modern Textiles, Conservation Science 2007 Archetype Publications, Milan, 2007, pp. 262-269.

[35] S. Kohijya, Y. Ikeda, Chemistry, Manufacture and Applications of Natural Rubber, Woodhead, London, 2014.

[36] Q. Zhao, X. Li, J. Gao, Aging of ethylene-propylene-diene monomer (EPDM) in artificial weathering environment, Polymer Degradation and Stability, 92 (2007) 1841-1846.

[37] S. Mitra, A. Ghanbari-Siahkali, P. Kingshott, S. Hvilsted, K. Almdal, An investigation on changes in chemical properties of pure ethylene-propylene-diene rubber in aqueous acidic environments, Materials Chemistry and Physics, 98 (2006) 248-255.

[38] R.P. Santos, M. Santos de Oliveira, E. da Costa Mattos, M.F. Diniz, R. de Cassa Lazzarini Dutra, Studies by FT-IR Technique and Adhesive Properties of Vulcanized EPDM Modified with Plasma, Journal of Aerospace Technology and Management, 5 (2013) 


\section{FIGURES CAPTIONS}

Figure 1 Images of the decorative hand mirror (A, Object 2) and the decorative mechanised fan (B, Object 8).

Figure 2 Comparison between the TR FT-IR spectrum of Object 8 (A) and the best matching spectrum (B) in SamCo database (058A - Cellulose nitrate - match 95\%), being both spectra reported as KK.

Figure 3 Image of the completely degraded imitation tortoiseshell sunglasses (Object 1).

Figure 4 Comparison between the KK TR FT-IR spectrum of Object 1 (A) and the best matching spectrum (B) (Regenerated Cellulose ICB00057 extracted from IRUG 2007 database.

Figure 5 Images of the playing cards (A, Object 9) and the decorative knife (B, Object10)

Figure 6 Comparison between the TR FT-IR spectrum of Object 9 (A) and the best matching spectrum (B) in SamCo database (049A - ivory - match 87\%), being both spectra reported as KK.

Figure 7 Images of the Galalith toy counters (A, Object 5), the decorative green button (B, Object $6)$ and the decorative white button $(\mathrm{C}$, Object 7$)$.

Figure 8 Comparison between the TR FT-IR spectrum of Object 5 (A) and the best matching spectrum (B) in SamCo database (004 - Casein formaldehyde - match $86 \%$ ), being both spectra reported as KK.

Figure 9 Images of the undegraded (Object 3) and naturally degraded (Object 4) rubber gloves.

Figure 10 Comparison between the TR FT-IR spectra of Object 3 (A), Object 4 (B) and the best matching spectrum (C) in SamCo database (024 - Polyethylene LD - match 95\%), being both spectra reported as KK.

Figure 11 Detail of the $\mathrm{KK}$ spectra shown in Figure 10 in which the presence of weak $\mathrm{C}=\mathrm{O}$ carbonyl vibration around $1700 \mathrm{~cm}^{-1}$ is broader and more evident for the heavily degraded glove (Object 4, black line ) than for the other (Object 3, grey line). 


\section{TABLE CAPTIONS}

Table 1. List of the objects (from the Materials Library of the Department of History of Art, University College London) analysed using non-invasive TR FT-IR, with description, hypothesized classification, and Spectral Assignment based on best matching obtained by means of Omnic search tool applied to the reference spectral library.

Table 2. FT-IR main absorption bands and their attributions for Object 8.

Table 3. FT-IR main absorption bands and their attributions for Object 1.

Table 4. FT-IR main absorption bands and their attributions for Object 9.

Table 5. FT-IR main absorption bands and their attributions for Object 5.

Table 6. FT-IR main absorption bands and their attributions for Objects 3 and 4. 
Table 1

\begin{tabular}{|c|c|c|c|c|c|}
\hline $\begin{array}{l}\text { Object } \\
\text { No. }\end{array}$ & $\begin{array}{c}\text { Object } \\
\text { Descrip on }\end{array}$ & $\begin{array}{l}\text { Approx. } \\
\text { Date }\end{array}$ & Condi on & $\begin{array}{l}\text { Hypothesized } \\
\text { Material }\end{array}$ & $\begin{array}{l}\text { FTIR Spectral Assignment based on } \\
\text { best matching spectra in the } \\
\text { SamCo-TR FT-IR spectral library }\end{array}$ \\
\hline 1 & Sunglasses & $1970 \mathrm{~s}$ & $\begin{array}{l}\text { Heavily degraded } \\
\text { exhibi ng migra on of } \\
\text { addi ves }\end{array}$ & $\begin{array}{l}\text { Cellulose } \\
\text { deriva ve with } \\
\text { triphenyl } \\
\text { phosphate }\end{array}$ & $\begin{array}{l}\text { ICB00057 IRUG - Viscose silk, Regenerated } \\
\text { Cellulose; match 87\% } \\
079 \text { Samco - Urea Formaldehyde; match 34\% } \\
049 \text { Samco - Bone; match 33\% }\end{array}$ \\
\hline 2 & $\begin{array}{l}\text { Decora ve } \\
\text { Hand } \\
\text { Mirror }\end{array}$ & $1930 \mathrm{~s}$ & $\begin{array}{l}\text { Heavily degraded } \\
\text { exhibi ng crazing. } \\
\text { Mirror showing signs of } \\
\text { corrosion }\end{array}$ & $\begin{array}{l}\text { Cellulose } \\
\text { nitrate }\end{array}$ & $\begin{array}{l}\text { 058A Samco - Cellulose nitrate; match 81\% } \\
009 \text { Samco - Cellulose nitrate; match } 79 \% \\
048 \text { Samco - Horn; match } 41 \%\end{array}$ \\
\hline 3 & Glove & $\begin{array}{l}\text { Early } \\
2000 s\end{array}$ & $\begin{array}{l}\text { Good condi on, } \\
\text { showing the ini al } \\
\text { stages of oxida on }\end{array}$ & $\begin{array}{l}\text { Unkown } \\
\text { Elastomer }\end{array}$ & $\begin{array}{l}024 \text { Samco - Polyethylene LD; match 95\% } \\
023 \text { Samco - Polyethylene MD; match 94\% } \\
066 \text { Samco - Polyethylene; match 89\% }\end{array}$ \\
\hline 4 & Glove & $\begin{array}{l}\text { Early } \\
2000 s\end{array}$ & $\begin{array}{l}\text { Heavily degraded, } \\
\text { exhibi ng } \\
\text { discoloura on and } \\
\text { embri lement } \\
\end{array}$ & $\begin{array}{l}\text { Unknown } \\
\text { Elastomer }\end{array}$ & $\begin{array}{l}022 \text { Samco - Polyethylene HD; match 93\% } \\
024 \text { Samco - Polyethylene LD; match 85\% } \\
023 \text { Samco - Polyethylene MD; match 85\% } \\
066 \text { Samco - Polyethylene; match 82\% }\end{array}$ \\
\hline 5 & $\begin{array}{l}\text { Galalith } \\
\text { Toy } \\
\text { Counters }\end{array}$ & $1930 \mathrm{~s}$ & Good condi on & $\begin{array}{l}\text { Casein } \\
\text { formaldehyde }\end{array}$ & $\begin{array}{l}048 \text { Samco - Horn; match } 86 \% \\
004 \text { Samco - Casein formaldehyde; match } 86 \% \\
054 \text { Samco - Casein formaldehyde; match } 75 \%\end{array}$ \\
\hline 6 & $\begin{array}{l}\text { Set of } \\
\text { Green } \\
\text { Bu ons }\end{array}$ & $1940 \mathrm{~s}$ & $\begin{array}{l}\text { Good condi on, } \\
\text { showing signs of fading }\end{array}$ & $\begin{array}{l}\text { Phenol } \\
\text { formaldehyde }\end{array}$ & $\begin{array}{l}048 \text { Samco - Horn; match } 82 \% \\
004 \text { Samco - Casein formaldehyde; match 80\% } \\
054 \text { Samco - Casein formaldehyde; match 73\% }\end{array}$ \\
\hline 7 & $\begin{array}{l}\text { Set of } \\
\text { White } \\
\text { Bu ons }\end{array}$ & $1950 \mathrm{~s}$ & Good Condi on & $\begin{array}{c}\text { Casein } \\
\text { formaldehyde }\end{array}$ & $\begin{array}{l}048 \text { Samco - Horn; match 79\% } \\
004 \text { Samco - Casein formaldehyde; match 74\% } \\
054 \text { Samco - Casein formaldehyde; match 58\% }\end{array}$ \\
\hline 8 & $\begin{array}{l}\text { Decora ve } \\
\text { Mechanise } \\
\text { d Fan }\end{array}$ & $1930 \mathrm{~s}$ & $\begin{array}{c}\text { Heavily degraded, } \\
\text { exhibi ng } \\
\text { embri lement and } \\
\text { exudate of addi ves on } \\
\text { surface. Metal } \\
\text { mechanism showing } \\
\text { signs of corrosion }\end{array}$ & $\begin{array}{l}\text { Cellulose } \\
\text { nitrate }\end{array}$ & $\begin{array}{l}\text { 058A Samco - Cellulose nitrate; match } 95 \\
009 \text { Samco - Cellulose nitrate; match 93\% } \\
048 \text { Samco - Horn; match } 47 \%\end{array}$ \\
\hline 9 & $\begin{array}{l}\text { Set of } \\
\text { Playing } \\
\text { Cards }\end{array}$ & $1940 \mathrm{~s}$ & $\begin{array}{l}\text { Good condi on, } \\
\text { showing some signs of } \\
\text { cracking }\end{array}$ & $\begin{array}{l}\text { Cellulose } \\
\text { acetate }\end{array}$ & $\begin{array}{l}\text { 049A Samco - Ivory; match } 87 \% \\
049 \text { Samco - Bone; match } 86 \% \\
054 \text { Samco - Casein formaldeide; match } 49 \%\end{array}$ \\
\hline 10 & $\begin{array}{c}\text { Decora ve } \\
\text { Knife } \\
\text { Handle }\end{array}$ & $1940 \mathrm{~s}$ & Good condi on & $\begin{array}{l}\text { Cellulose } \\
\text { acetate }\end{array}$ & $\begin{array}{l}\text { 049A Samco - ivory - match } 89 \% \\
049 \text { Samco - bone - match } 80 \% \\
061 \text { Samco - Phenol Formaldehyde match } 43 \%\end{array}$ \\
\hline
\end{tabular}


Table 2

\begin{tabular}{|c|c|}
\hline Wavenumber/cm & Attribution \\
\hline 2932,2860 & aliphatic C-H asymmetric and symmetric stretching \\
\hline 1646 & nitrate asymmetric stretching \\
\hline 1431 & H-C-H and O-C-H in plane bending \\
\hline 1371 & C-H in plane bending \\
\hline 1320 & $\mathrm{CH}_{2}$ rocking \\
\hline 1280 & Nitrate symmetric stretching \\
\hline 1160 & C-O-C asymmetric stretching \\
\hline 1116 & C-O-C symmetric stretching \\
\hline 1062,1000 & C-C, C-OH, C-H ring and side groups vibrations \\
\hline 840 & N-O stretching \\
\hline 750,677 & nitrate bending \\
\hline
\end{tabular}


Table 3

\begin{tabular}{|c|c|}
\hline Wavenumber/cm & Attribution \\
\hline$\sim 3400$ & $\mathrm{O}-\mathrm{H}$ intramolecular H bonding \\
\hline $2926,2905,2886$ & aliphatic C-H asymmetric and symmetric stretching \\
\hline$\sim 1650$ & OH bending \\
\hline 1420 & $\mathrm{H}-\mathrm{C}-\mathrm{H}$ and O-C-H in plane bending \\
\hline 1372 & $\mathrm{C}-\mathrm{H}$ in plane bending \\
\hline 1310 & $\mathrm{CH}_{2}$ rocking \\
\hline 1232 & $\mathrm{COH}$ bending \\
\hline 1160 & $\mathrm{C}-\mathrm{O}-\mathrm{C}$ asymmetric stretching \\
\hline 1115 & $\mathrm{C}-\mathrm{O}-\mathrm{C}$ symmetric stretching \\
\hline $1075,1030,1000$ & $\mathrm{C}-\mathrm{C}, \mathrm{C}-\mathrm{OH}, \mathrm{C}-\mathrm{H}$ ring and side groups vibrations \\
\hline 900 & COC, CCO, CCH deformation \\
\hline 665 & C-OH out of plane bend \\
\hline
\end{tabular}


Table 4

\begin{tabular}{|c|c|}
\hline Wavenumber/cm & Attribution \\
\hline 3315 & N-H stretching \\
\hline $2954,2924,2853$ & aliphatic C-H asymmetric and symmetric stretching \\
\hline 1736 & C=O stretching (probable traces of fat) \\
\hline 1660 & Amide I band (C=O stretching amide) \\
\hline 1553 & Amide II band (N-H bending) \\
\hline 1453 & C-H bending \\
\hline 1415 & C-N stretching \\
\hline 1258 & interaction between NH bending and CN stretching of C-N-H group \\
\hline $1095,1040,961$ & C-O-C asymmetric stretching \\
\hline 1115 & C-O-C symmetric stretching \\
\hline $1075,1030,1000$ & phosphate ion stretching \\
\hline 607,568 & phosphate ion bending \\
\hline
\end{tabular}


Table 5

\begin{tabular}{|c|c|}
\hline Wavenumber/cm & Attribution \\
\hline 3285,3070 & N-H stretching \\
\hline 2950,2840 & aliphatic C-H asymmetric and symmetric stretching \\
\hline 1650 & Amide I band (C=O stretching amide) \\
\hline 1542 & Amide II band (N-H bending) \\
\hline 1448 & C-H bending \\
\hline 1393 & C-N stretching \\
\hline 1242 & interaction between NH bending and CN stretching of C-N-H group \\
\hline
\end{tabular}


Table 6

\begin{tabular}{|c|c|}
\hline Wavenumber/cm & Attribution \\
\hline $2954,2921,2851$ & aliphatic $\mathrm{C}-\mathrm{H}$ asymmetric and symmetric stretching \\
\hline 1469 & $\mathrm{C}-\mathrm{H}$ bending \\
\hline 722 & $\mathrm{CH}_{2}$ rocking \\
\hline
\end{tabular}




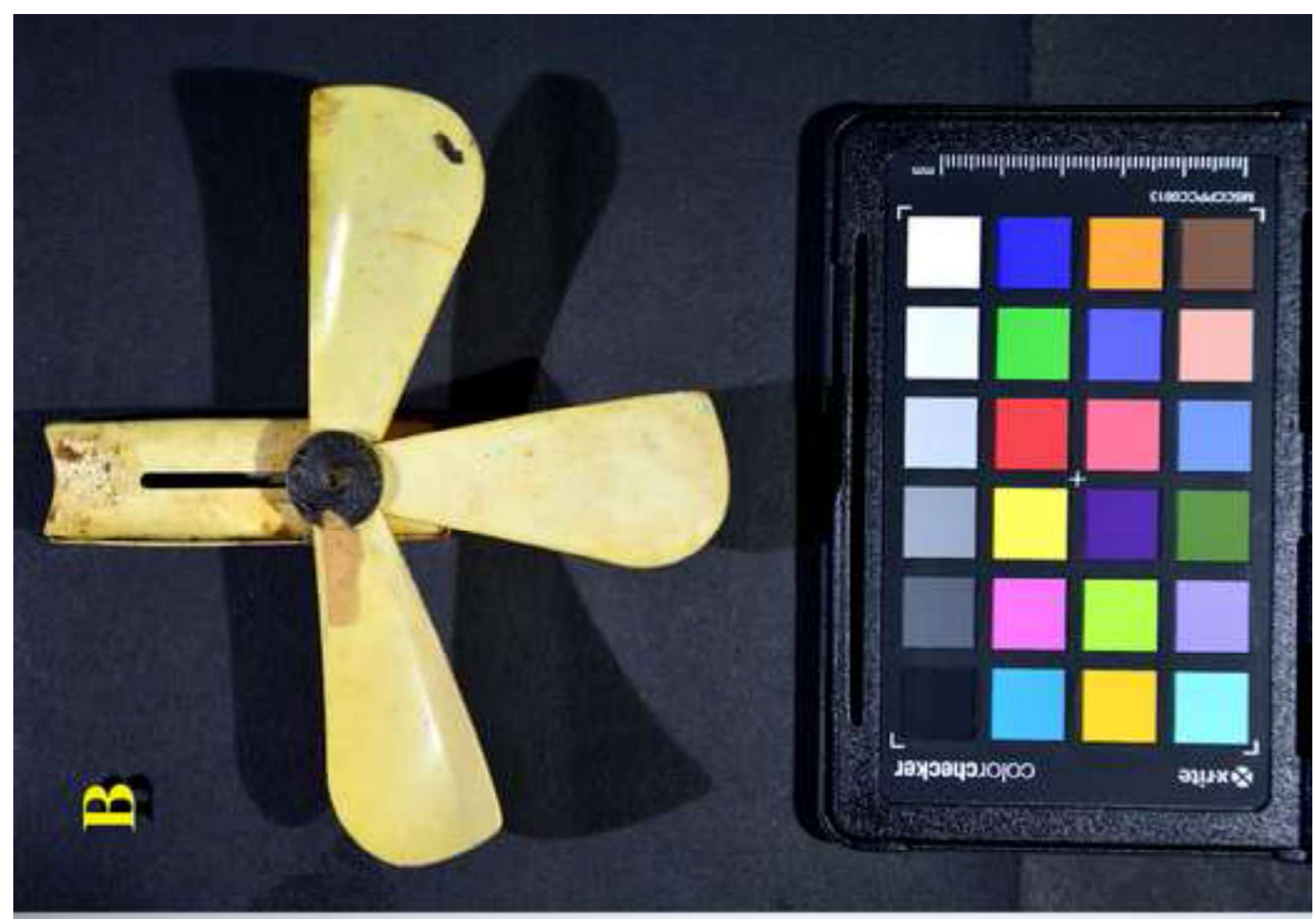

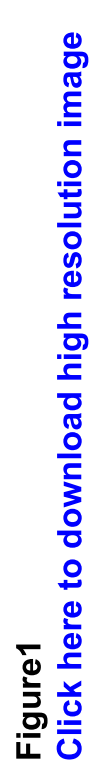




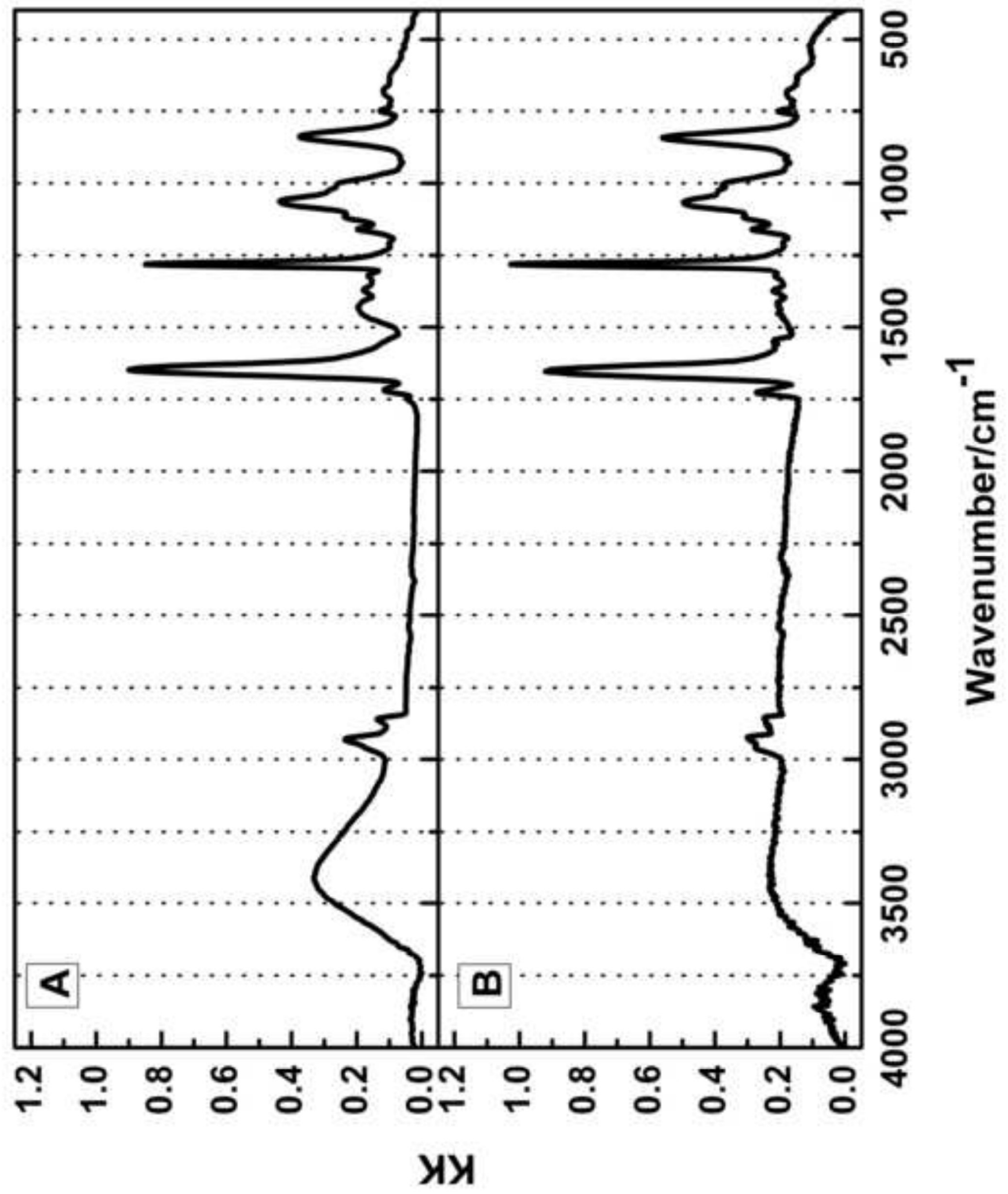




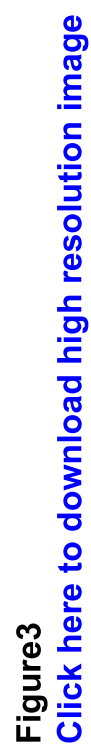

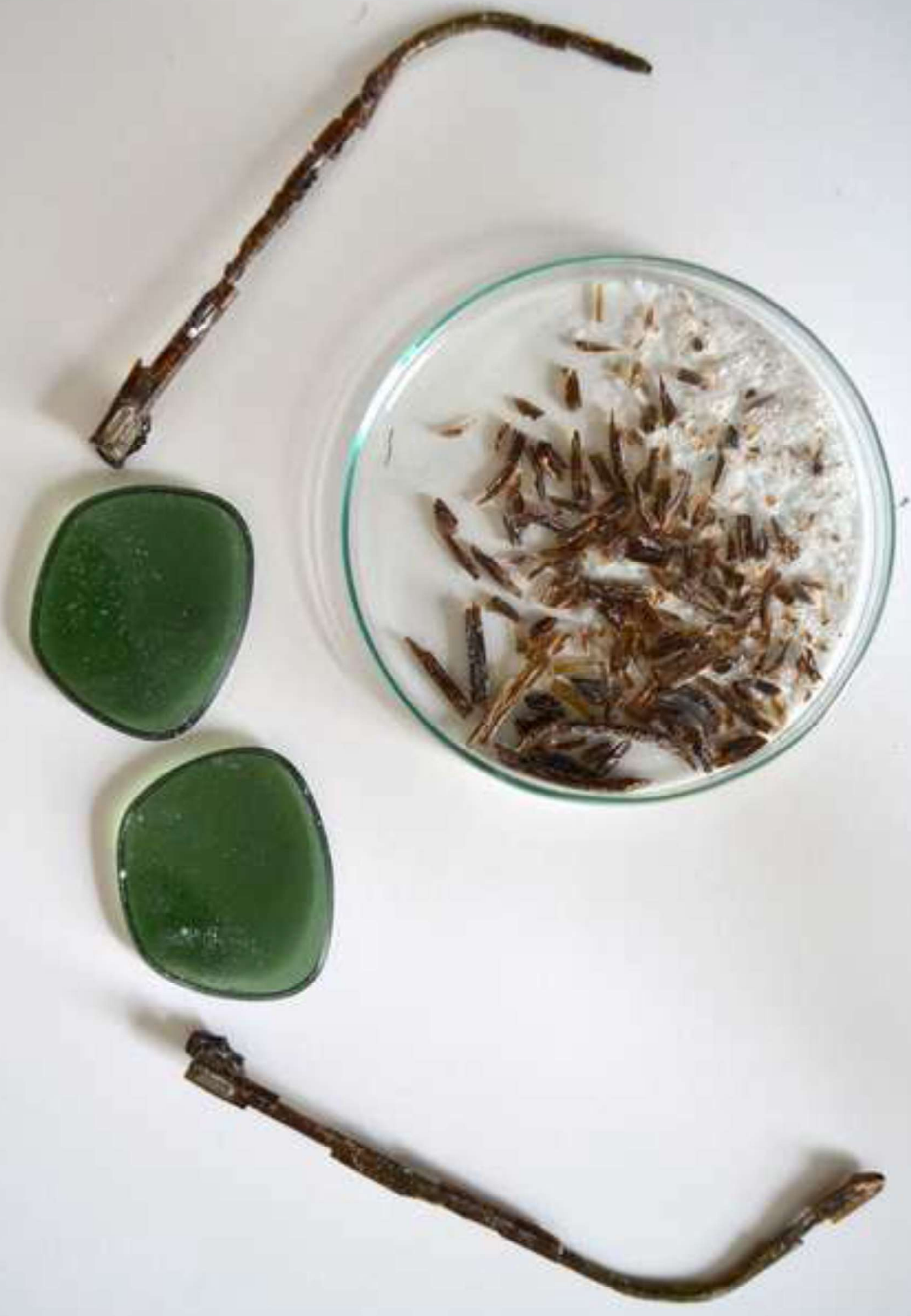




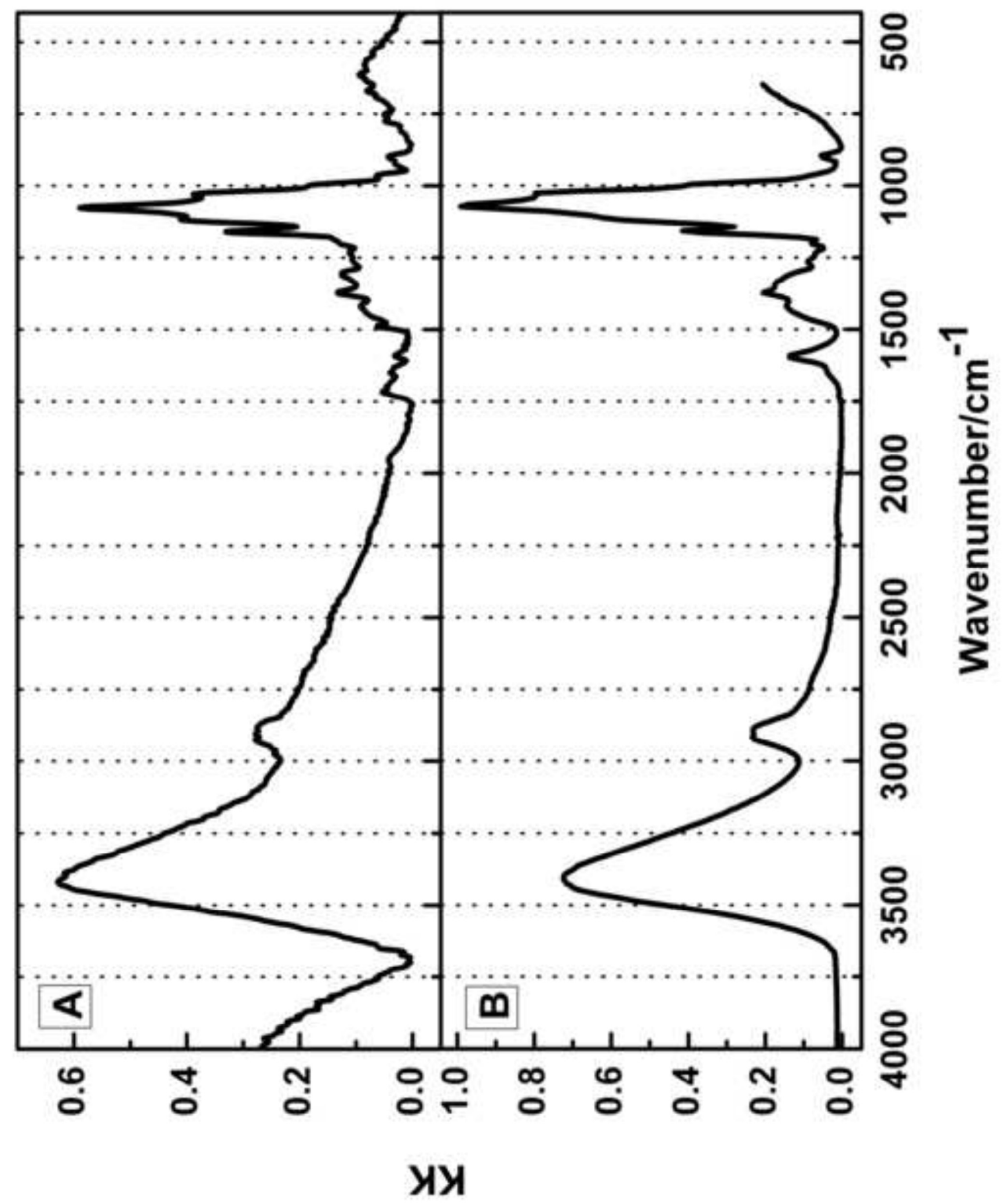




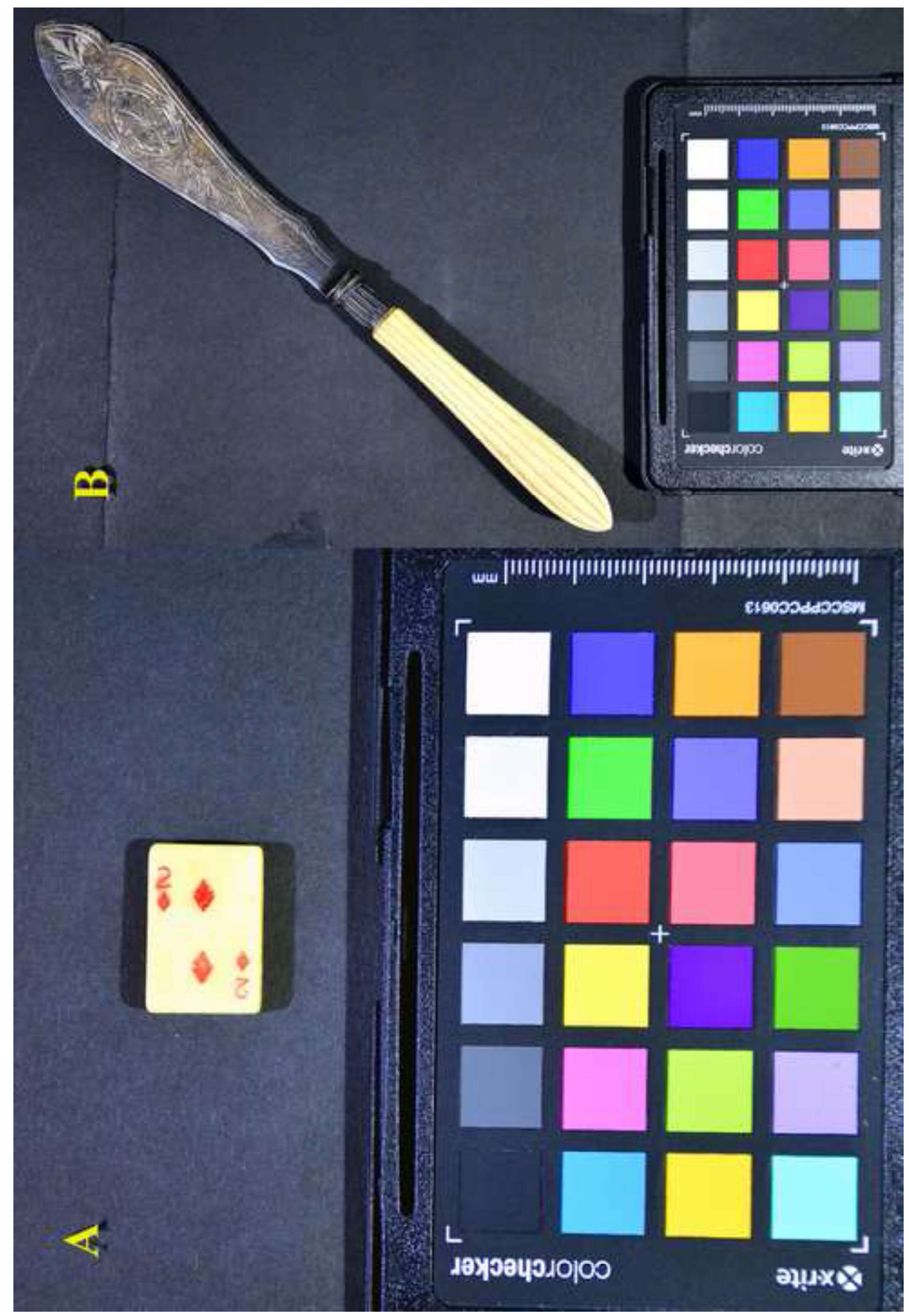

氕

iㄴ 


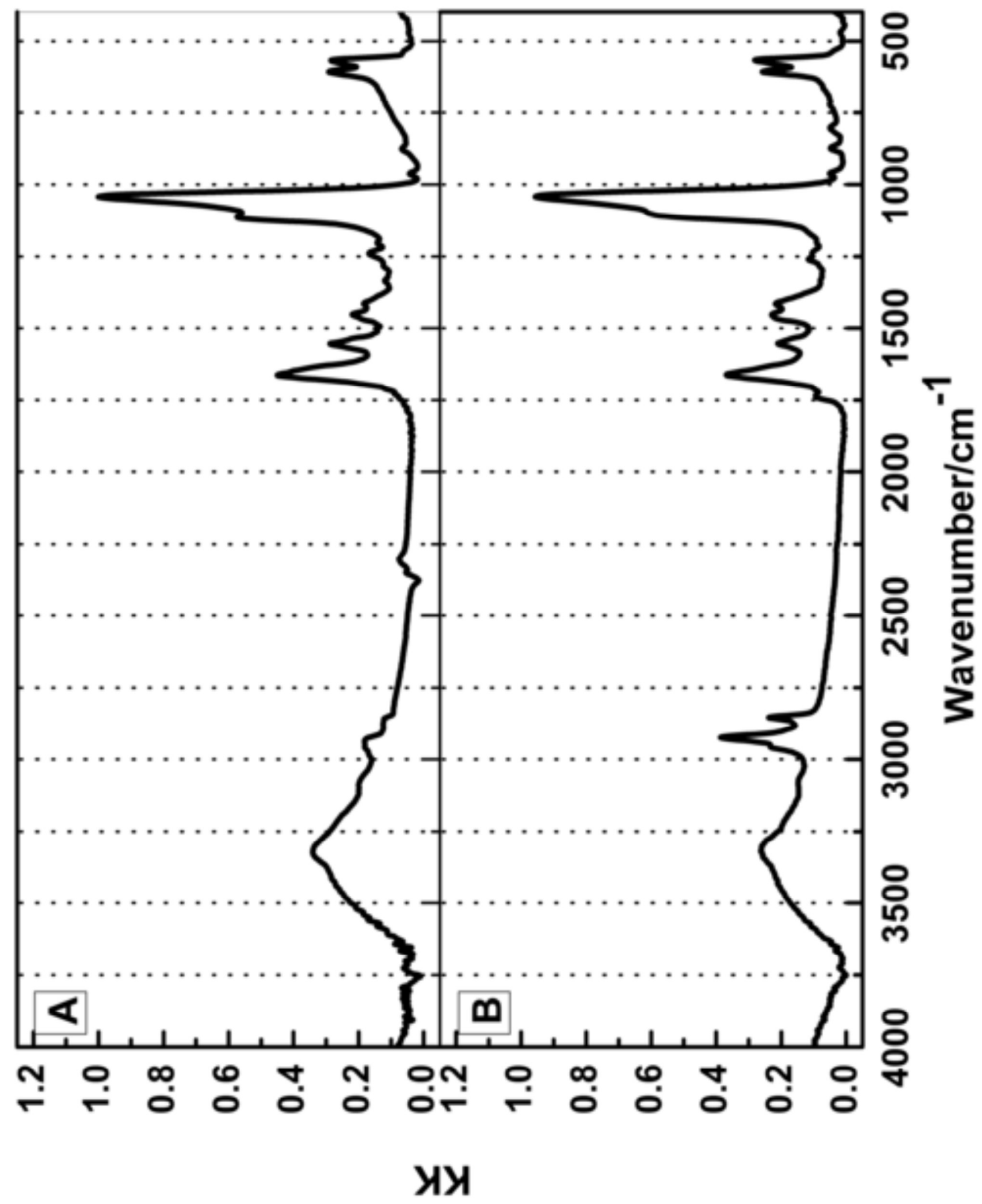




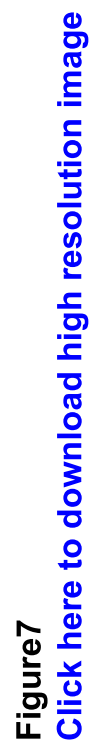

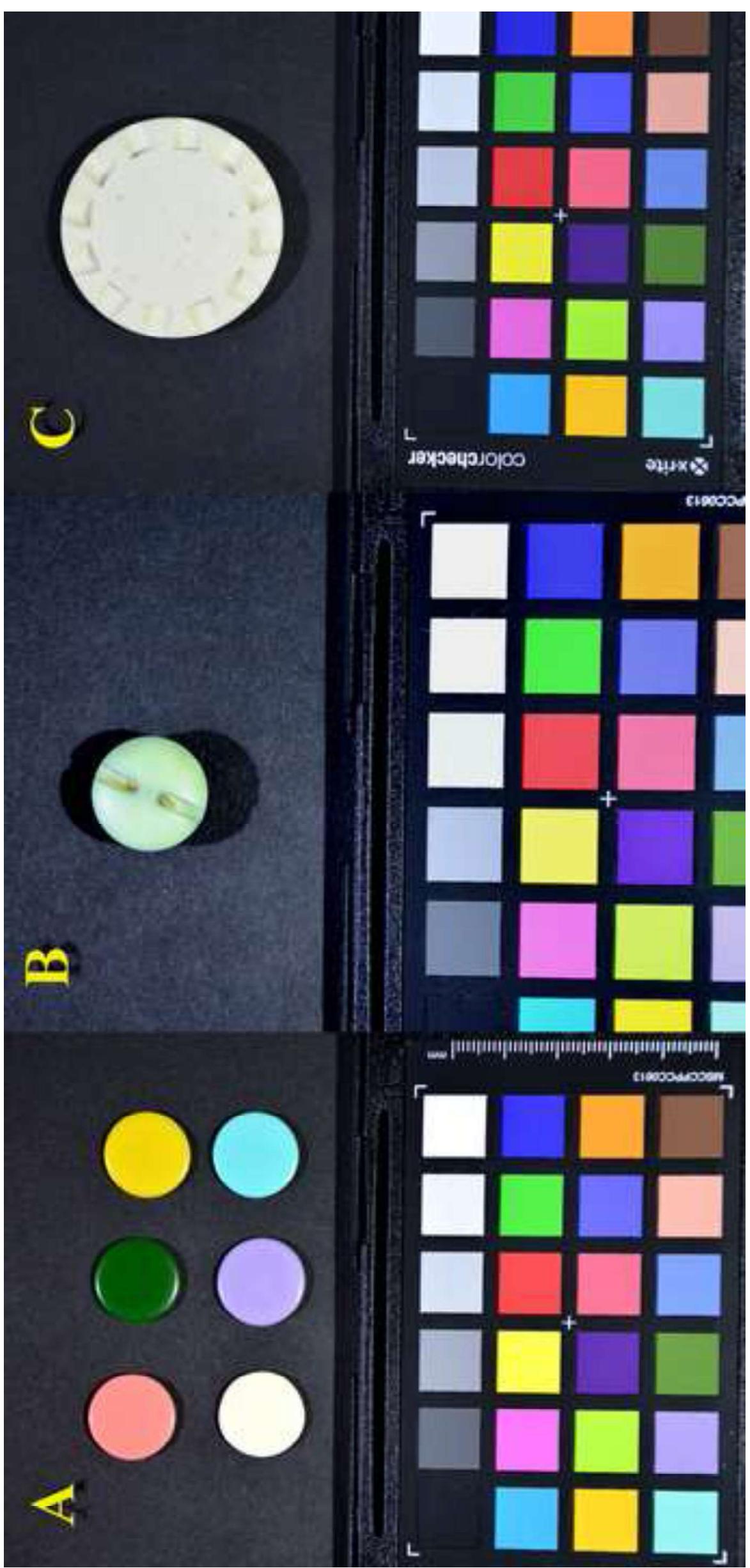




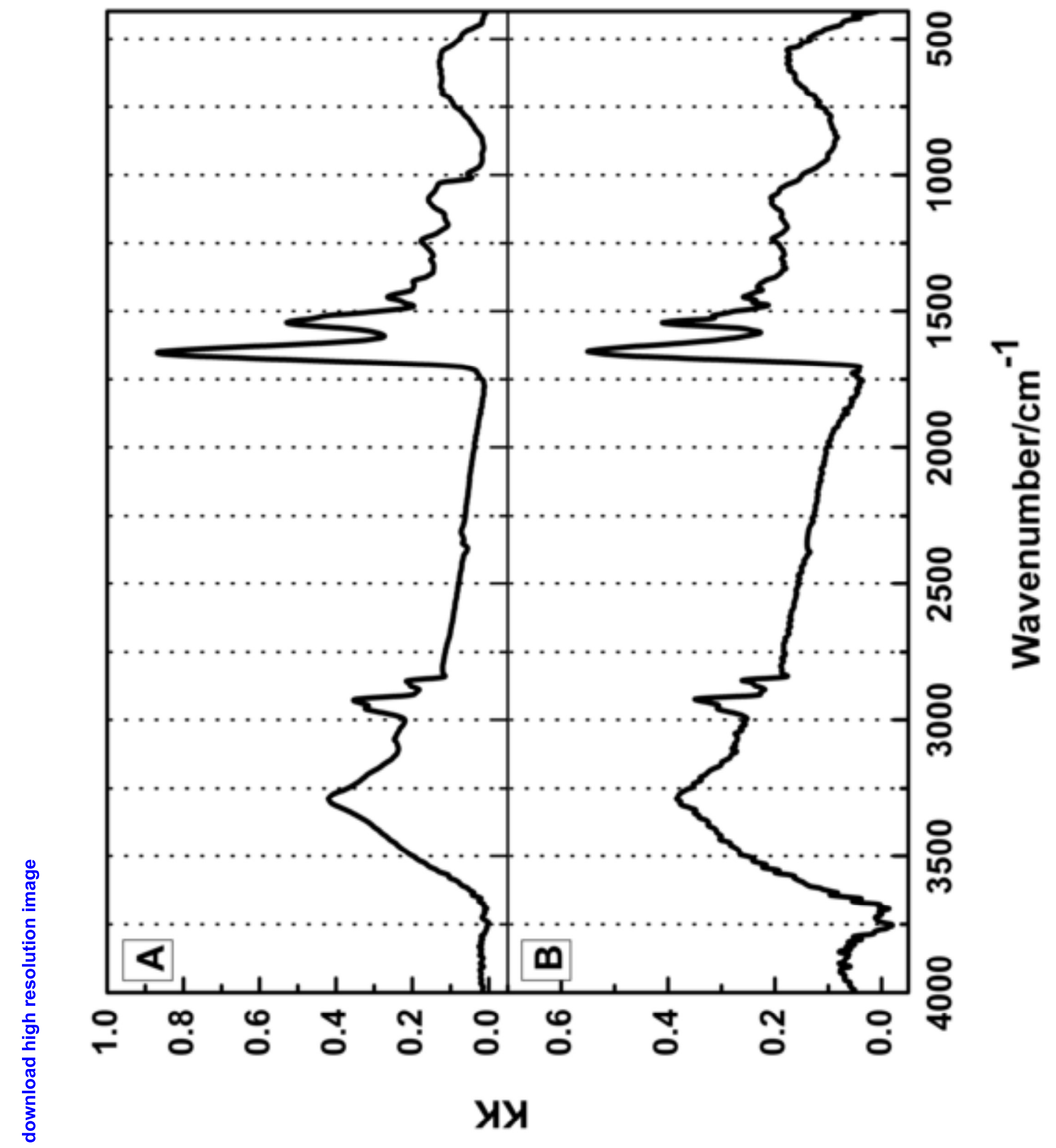




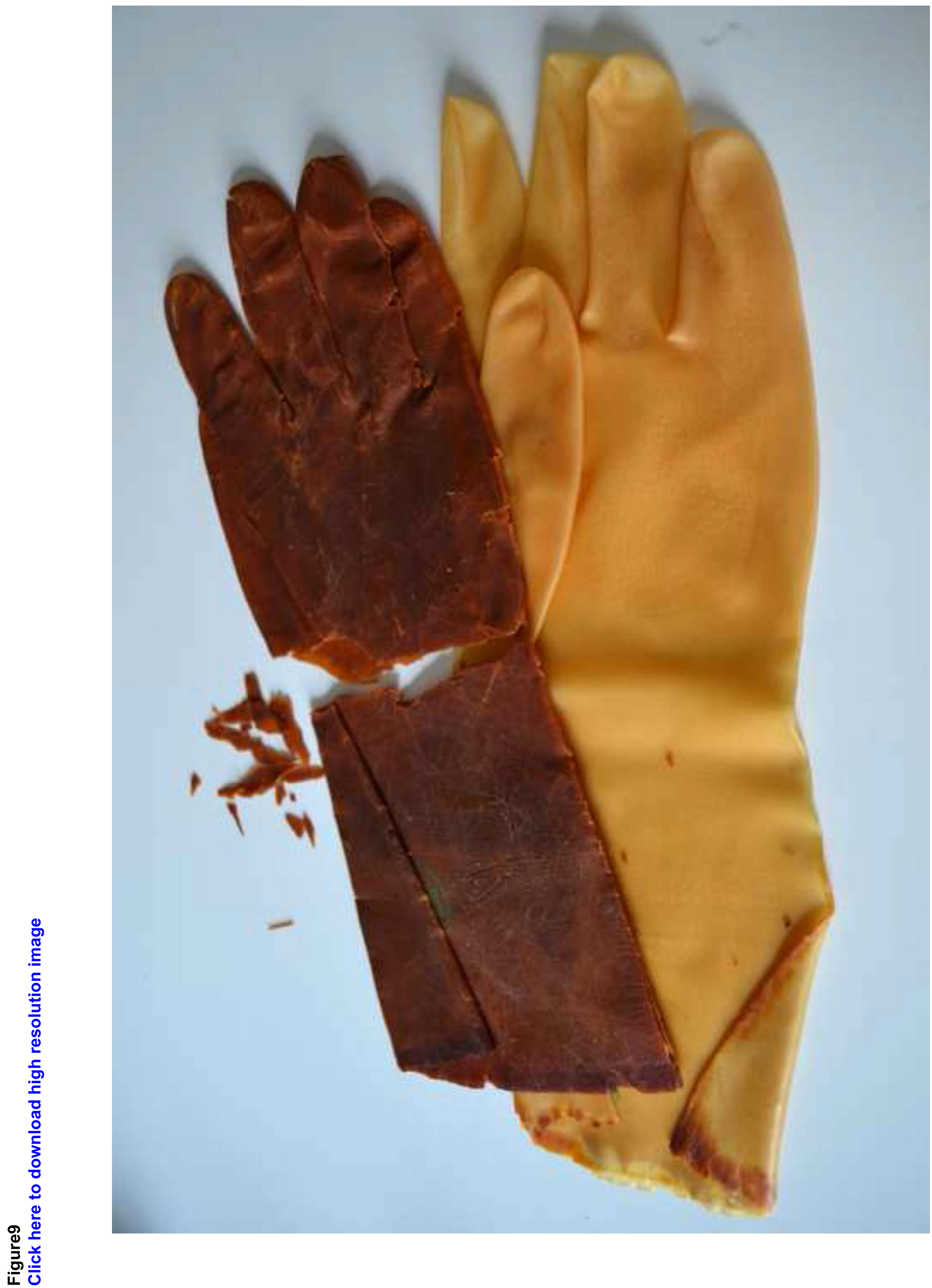




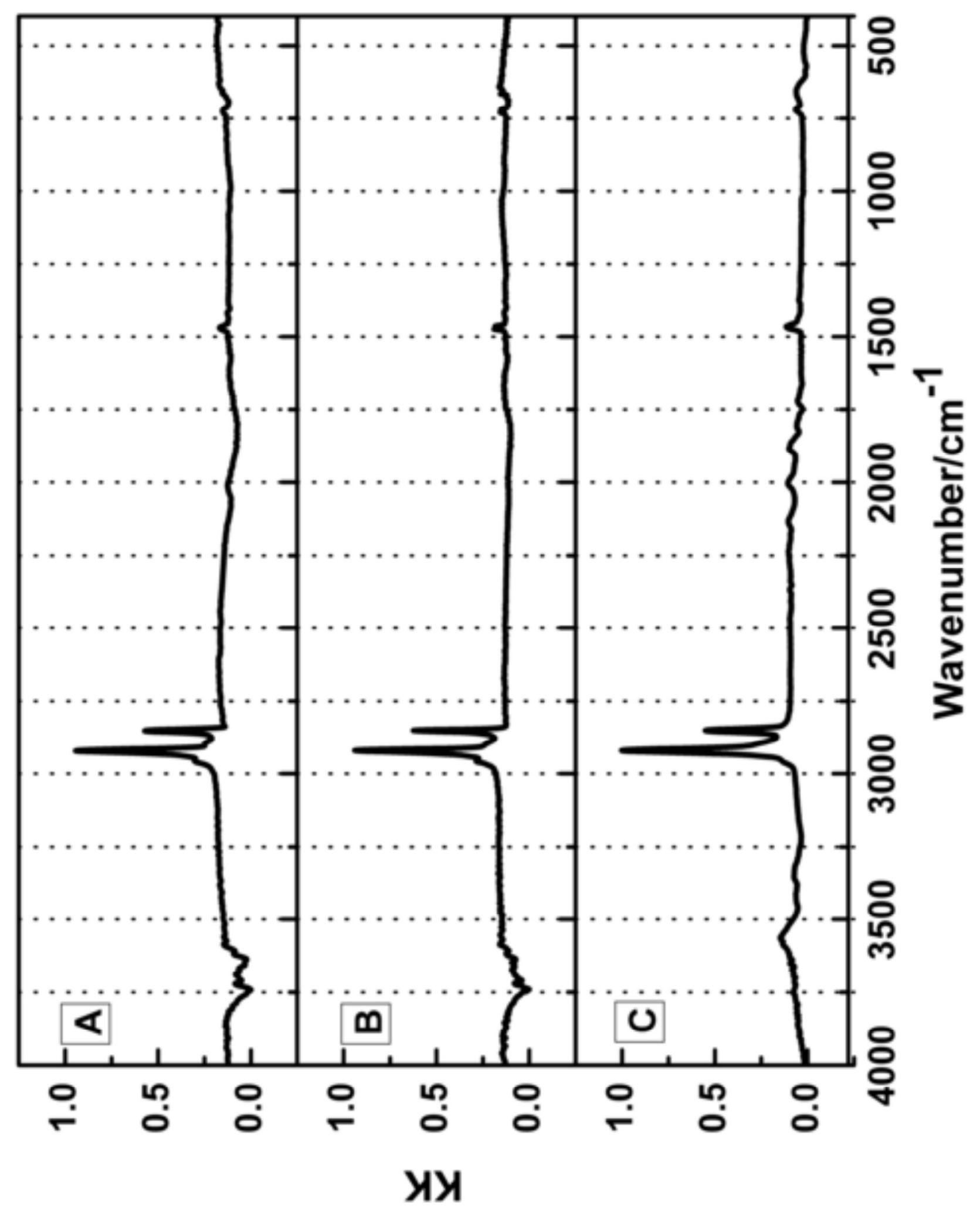




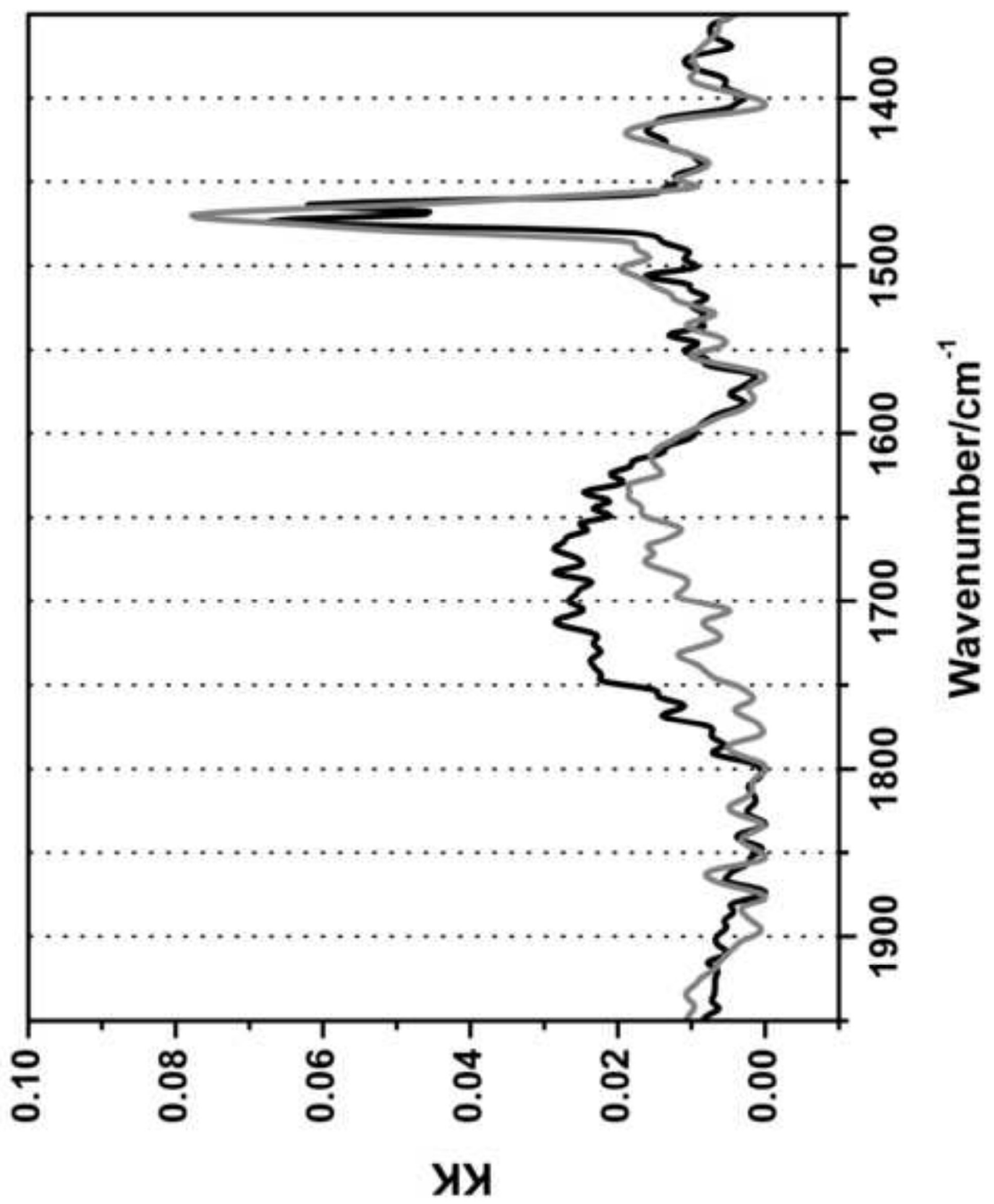

